\title{
An Exploration of the needs of a Cardiac Rehabilitation Population using a Subjective Quality- of-Life Measure
}

\author{
Emily Basquille, ${ }^{1}$ Verna McKenna, ${ }^{1}$ Ailish Houlihan, ${ }^{2}$ Kate Molony, ${ }^{3}$ Dr. Veronica McInerney, ${ }^{4}$ \\ Dr. Eileen Mannion ${ }^{5}$ Dr. John Barton, ${ }^{6}$ Prof Dympna Waldron ${ }^{5,7}$ \\ ${ }^{1}$ School of Health Science, Health Promotion, National University of Ireland Galway (NUIG), Ireland \\ ${ }^{2}$ Self-management Support Co-ordinator, Community Healthcare West, HSE, Ireland \\ ${ }^{3}$ Department of Psychology, Graduate, NUIG, Ireland \\ ${ }^{4}$ HRB Clinical Research Facility and School of Nursing and Midwifery, NUIG, Ireland \\ ${ }^{5}$ Department of Palliative Medicine, University Hospital Galway, Saolta Hospitals Group (SHG), Ireland \\ ${ }^{6}$ Department of Cardiology, University Hospital Galway, SHG, Ireland \\ ${ }^{7}$ Department of Medicine, NUIG, Ireland
}

Corresponding Author: Prof Dympna Waldron; dympnamwaldron@gmail.com

Received 30 April 2020;

Accepted 26 May 2020;

Published 15 June 2020

\begin{abstract}
Context: The aim of this study was to profile a cardiac rehabilitation population in the West of Ireland and establish Subjective Quality of Life (SQoL), using The Schedule for Evaluation of Individual Quality of Life-Direct Weighting (SEIQoL-DW), a validated subjective QoL measure. Bothersome symptoms (SB) and Symptom Interference in SQoL (SBIQoL) were also assessed using a using a modified SEIQoL-DW. Objectives: QoL is a difficult concept to define, therefore the medical profession often premise QoL on health and illness. The focus of this study was to explore the QoL needs of a cardiac population, with a view to informing the development of a newly formed cardiac rehabilitation support group. The SEIQoL-DW was developed to overcome the limitations of quantitative questionnaires, as it is based on the individual's personal view of life and its quality. Methods: SQoL, symptoms and SBIQoL, of 22 individuals, who had suffered a cardiac event were explored. SEIQoL-DW is a semi-structured interview, enabling the individual to convert their perspectives into scientific values. QoL areas of importance to patients are called 'cues'. A modified SEIQoL-DW was used to assess SB and SBIQoL. Data were analysed using both quantitative analysis and qualitative descriptive analysis. Findings: Participants highlighted a range of QoL cues; findings from this study showed that $45 \%$ of participants did not rate 'health' in the first five QoL cues. A significant number of participants experienced symptoms; a medium negative correlation was found between symptom interference and QoL, rho $=-0.353$, with high levels of symptom interference associated with low levels of QoL. Conclusions: The range of QoL cues and bothersome symptoms identified in this study had implications for the development of the group, with participants eager to participate and talk candidly about their needs. SEIQoL-DW proved to be an acceptable, reliable and valid technique for measuring both individual QoL, SB and SBIQoL, taking greater consideration of individual perspectives compared with traditional measurement approaches. The significance of nominated symptoms and SBIQoL warrants further attention, especially if these symptoms are reversible.
\end{abstract}

Keywords: Subjective Quality of Life (SQoL), Schedule for Evaluation of Individual Quality of Life-Direct Weighting (SEIQoL-DW), Symptom bother/interference with Quality of Life (SBIQoL), Symptom Bother (SB), Info-Graph

\section{Introduction}

During the past decade a paradigm shift has occurred in the measurement of QoL from the use of standardised questionnaires towards a more individual approach. ${ }^{[1-22]}$ The multi-dimensional aspects of QoL make it a difficult concept to define, hence it has traditionally been measured based on health and illness. ${ }^{[23-35]}$ Similarly, patient nominated symptoms and the degree to which they interfere with QoL should be based on the patient's perspectives. ${ }^{[20-22]}$ The Schedule for the Evaluation of Quality of Life (SEIQoL) and SEIQoL-DW were developed to overcome the limitations of quantitative prejudged questionnaires, as it is based on the individual's personal view of life and its quality and both are well validated. ${ }^{[1-6,10-16]}$ Because of the amorphous and multidimensional nature of QoL, most researchers in medicine and health care concern themselves with a sub-component of QoL 
which has been termed health-related QoL (HRQoL). ${ }^{[23-38]}$ This is distinct from QoL as a whole, which would also include such components as adequacy of education, housing, income and perceptions of the immediate environment. There is broad agreement that in measuring HRQoL, we should assess a number of crucial areas including physical function, psychological state, somatic symptoms such as pain, social function including relationships, sexual function and occupational function and possibly financial state. We should include some assessment of the patient's level of general well-being, satisfaction with treatment, outcome and health-status and with future prospects. The concept of HRQoL, owes much to the original WHO definition of health as it emphasises mental and social well-being and not just the absence of disease. The WHOQoL group used the following definition underpinning the development of a core specific QoL measure. ${ }^{[35]}$ "Quality of life is defined as the individual's perception of their position in life in the context of the culture and value systems in which they live and in relation to their goals, expectations, standards and concerns. It is a broad ranging concept affected in a complex way by a person's physical health, psychological state, level of independence and their relationships to salient features of their environment."

Patrick and Erickson, ${ }^{[38]}$ define HRQoL as "the value assigned to the duration of life as modified by the social opportunities, perceptions, functional states and impairments that are influenced by disease, injuries, treatments or policy." This definition of HRQoL is clear and succinct but it places health at the heart of the QoL concept and it is questionable if this is accurate. HRQoL measures can provide invaluable information about how a person's health is affecting his/ her life. However, are they really measuring QoL? Does everyone's QoL revolve around health.? Patients with advanced cancer define health as "a sense of personal integrity and wholeness rather than normal physical, emotional and social functioning". [39]

Evaluation of service provision is an important part of assessing the impact of an intervention for people's cardiac condition and QoL. ${ }^{[40-49]}$ Measurement instruments may be 'generic', providing a broad assessment of someone's health status. Such instruments used in heart disease include the Nottingham Health Profile (NHP), ${ }^{[50]}$ the Short Form 36 (SF-36), ${ }^{[51,52]}$ and the Sickness Impact Profile (SIP). ${ }^{[53]}$ Instruments may also be 'disease specific', encompassing domains or areas closely related to the clinician's remit; such instruments tend to be more sensitive to change in health status related to a specific disease. They include measures such as, QoL after Myocardial Infarction (QLMI), ${ }^{[54]}$ the Seattle Angina Questionnaire (SAQ) ${ }^{[55]}$ the QoL Index-Cardiac Version (QoL-CV), ${ }^{[56]}$ and the Angina Pectoris QoL Questionnaire (APQoLQ). ${ }^{[57]}$ While HRQoL measures provide important information regarding health status, their promulgation as measures of QoL are more questionable. It may be argued that all QoL instruments face the same problem, finding an agreed criterion or 'gold standard' against which different instruments can be judged. ${ }^{[1-6,58,59]}$ The SEIQoL-DW is a measure that overcomes the problem of pre-determined domains in questionnaires, which impose an external value system on participants. Participants parttake in a semi-structured interview during which they nominate the domains of meaning to their SQoL and enables a person-centred approach to practice. The global index score derived from the process provides a quantitative measure, which is useful when comparing different populations. Incorporating the patient's perspective about decisions that affect their SQoL can illuminate ideological struggles between providers, who adopt a rational, objective view, and patients, who have a subjective perspective on their unique experience. ${ }^{[1-5,58,59]}$

A study in the area of limb-saving surgery by Sugarbaker et $\mathrm{al},{ }^{[59]}$ found that their hypothesis, 'surgery plus irradiation would provide improved QoL compared to amputation', was not substantiated. However, Coates et al, ${ }^{[27]}$ found that continuous chemotherapy for patients with advanced breast cancer resulted in improved QoL for patients when compared to a control group receiving intermittent chemotherapy. Temel et al, ${ }^{[60]}$ reported lung cancer patients lived longer with earlier palliative care involvement, raising very complex questions concerning QoL/symptom control and the positive impact that would have on prolongation of 'actual' life.

\section{Defining Quality of Life:}

The multi-dimensional facets of QoL have led to general discord in defining and conceptualising the phenomenon. Interest in QoL ranges from the environment, to evaluation of the benefit/burden ratio of medical treatments, to the marketing of products we buy. Policy affecting QoL spans recreation, employment, transport, housing, environmental and conservation issues, the visual arts and health. ${ }^{[2,3]}$ On an individual level, QoL is influenced by both intrinsic and extrinsic factors, including hopes, expectations, disappointment and joys, social circumstances, disease, illness, disability, financial status, family, employment status and so on. It is the layers of influence on QoL, so unique to each person, that make its' definition so challenging. What researchers and clinicians do agree on is the fact that QoL has subjective and multidimensional aspects. $[1,5,35-37,61-68]$

Attempts to define QoL are nonetheless ongoing. Calman, ${ }^{[68]}$ defined QoL "as the difference, or gap at a particular point in time, between the hopes and expectations of the individual and that individual's present experience." Raphael et al, ${ }^{[69]}$ defined QoL as the degree to which a person enjoys the important possibilities of their life, and like Calman viewed it as a concept unique to the individual. Campbell et al, ${ }^{[25]}$ described QoL as " $a$ vague and ethereal entity, something that many people talk about, but which nobody very clearly knows about." Other investigators make no attempt to define it at all. The World Health Organisation considers cultural and value systems of QoL. ${ }^{[35]}$

Wolfensberger et al ${ }^{[70]}$ claimed that $Q o L$ was a hopeless term', indeed, the lack of agreement on its definition highlights the complexity of the concept, leaving it open to socio-political trends and policies. In the past two decades, the subjective nature of QoL has received increased recognition; Matti Hayry, ${ }^{[71]}$ viewed it as "being no more nor less than what someone considers it to be." Cohen et al, ${ }^{[29]}$ refers to the human plan of life and the inter-related purposes that gives a person's life unity and meaning. The definition that underpins this research study is that " $Q o L$ is what the patient determines it to be $e^{,[1-7,9-22]}$. This person-centred approach is a practice in health promotion that sees people using social and health services as equal partners. Theoretically, putting people and their families at the centre of decisions, working alongside health professionals, results in better outcomes for all stakeholders.

\section{Schedule for the Evaluation of Quality of Life (SEIQoL) - Direct Weighting (SEIQoL-DW):}

A review in the late nineteen nineties of validated QoL assessments outcome measures available for use in patients with life-limiting illnesses, highlighted that the SEIQoL methodology would appear to be the most appropriate measure to use to begin the study of QoL, from the individual's perspective, in this patient group. The SEIQoL was developed specifically as an individual measure of 
QoL. It is therefore ideally suited for use in single subject design and within-subject study designs in which respondents act as their own controls. However, it is also possible to use the SEIQoL in between subject comparison studies, using the SEIQoL index score. Reducing SEIQoL information to summary scores and grouped data does compromise the individual nature of the measure. The individual patient profile result could be used in clinical situations to add information on the patient's view of their QoL. ${ }^{[1,14-16,23,25]}$

The SEIQoL and the SEIQoL-DW are SQoL measure based on the individual's personal view of life and its quality. In judging SQoL the individual evaluates salient areas of their life and how they are doing in these areas. The measure was designed to answer three questions about a person's SQoL:

- What areas of life are important to the respondent (cues) - elicited by means of a structured interview.

- How the individual is currently doing in each of these areas (levels) - measured on a visual analogue scale.

- What is the relative importance of each of these areas (weights) - determined with a technique called Judgement Analysis (JA).

JA is a research method often used in studies of judgement and decision-making. (Judgement analysis through multiple regression analysis) It externalises the manner in which a person makes a judgement or decision. Its' goal is to quantify the relationship between the judgement and the information used to make that judgement. Therefore, its use with patients who may be cognitively impaired may be problematic. ${ }^{[19,41]}$

Table 1: Top QoL 'cues' in previous studies:

\begin{tabular}{|c|c|c|c|c|c|c|c|c|}
\hline Cues & $\begin{array}{l}\mathrm{n}=80 \\
\text { Pall. } \\
\text { Care }\end{array}$ & $\begin{array}{l}n=33 \\
\text { HIV } \\
\text { Asymp- } \\
\text { tomatic }\end{array}$ & $\begin{array}{l}\mathrm{n}=19 \\
\text { HIV } \\
\text { Sympto- } \\
\text { matic }\end{array}$ & $\begin{array}{l}n=56 \\
\text { Healthy } \\
\text { Elderly }\end{array}$ & $\begin{array}{l}\mathrm{n}=20 \\
\mathrm{OA} \\
\text { Group }\end{array}$ & $\begin{array}{l}n=20 \\
\text { PUD } \\
\text { Group }\end{array}$ & $\begin{array}{l}\mathrm{n}=20 \\
\text { IBS } \\
\text { Group }\end{array}$ & $\begin{array}{l}n=40 \\
\text { Healthy } \\
\text { young }\end{array}$ \\
\hline & $\%$ & $\%$ & $\%$ & $\%$ & $\%$ & $\%$ & $\%$ & $\%$ \\
\hline Family & 94 & 61 & 83 & 89 & 70 & 100 & 95 & 62 \\
\hline Health & 69 & 70 & 72 & 91 & 50 & 60 & 80 & 83 \\
\hline $\begin{array}{l}\text { Social Life/ } \\
\text { Leisure Time }\end{array}$ & 45 & 30 & 33 & 95 & 75 & 75 & 75 & 38 \\
\hline $\begin{array}{l}\text { Religion/ } \\
\text { Spiritual life }\end{array}$ & 38 & 9 & 28 & 75 & 45 & 5 & 5 & 7 \\
\hline $\begin{array}{l}\text { Friends/ } \\
\text { Relationship }\end{array}$ & 38 & 30 & 33 & 18 & 45 & 50 & 55 & 86 \\
\hline $\begin{array}{l}\text { Contented/ } \\
\text { Happiness }\end{array}$ & 28 & 33 & 17 & 5 & 5 & 15 & 30 & 48 \\
\hline $\begin{array}{l}\text { Work } \\
\text { Finances }\end{array}$ & $\begin{array}{l}19 \\
19\end{array}$ & $\begin{array}{l}15 \\
61\end{array}$ & $\begin{array}{l}6 \\
56\end{array}$ & $\begin{array}{l}5 \\
25\end{array}$ & $\begin{array}{l}45 \\
50\end{array}$ & $\begin{array}{l}75 \\
35\end{array}$ & $\begin{array}{l}55 \\
60\end{array}$ & $\begin{array}{l}38 \\
60\end{array}$ \\
\hline
\end{tabular}

PUD-Peptic Ulcer Disease; IBS-Irritable Bowel Syndrome

Waldron et al, ${ }^{5}$

\section{Symptom Bother/Symptom Interference with the SQoL in a Cardiac Population:}

Controlling patients' symptoms is a salient aspect of clinical care, and complex symptoms are relatively common for patients who have experienced a cardiac event. ${ }^{[45]}$ The degree to which symptoms impact on a patient's SQoL may affect how they live their life, particularly in the context of one's hopes and dreams. In treating cardiac patients, clinicians may often concentrate on what
A simpler, more efficient clinical tool was then developed to measure SQoL based on the concept of SEIQoL. A directweighting procedure (SEIQoL-DW) for QoL domains has proven more suitable for routine clinical use than SEIQoL(uses JA, and may pose fewer demands on people with reduced cognitive functioning. ${ }^{[41]}$ The first study carried out using SEIQoL-DW comprised a group of 42 healthy adults (20 males and 22 females) attending an immunisation clinic before travelling abroad. ${ }^{[13]}$ Many cues elicited, were not typically assessed by standardised instruments, for example politics, aesthetics and the environment. This first use of SEIQoL-DW proved acceptable and feasible in a healthy adult population. Internal consistency and validity of information were found to be high, achieving the aim of this crosssectional study. Waldron et al, ${ }^{[5]}$ also found that JA may measure unconscious thought, while SEIQoL-DW may measure conscious thought which has more relevance to clinical practice. As SEIQoLDW is also much quicker, ${ }^{[6]}$ ten minutes on average, it also has an acceptable application in clinical studies. Table 1, below summarises the top eight cues nominated in a variety of studies that used the SEIQoL-DW subjective measure.

The SEIQoL-DW measure has been applied to a variety of cohorts, highlighting the acceptability of SEIQoL-DW to a number of different patient groups. ${ }^{[19]}$ The first clinical application of SEIQoL-DW was with a group of 52 patients with HIV/AIDS. ${ }^{[6]}$ It was subsequently shown to be acceptable to patients with; terminal cancer; ${ }^{[5,9,10,14-16,63,72-75]}$ severely advanced multiple sclerosis ${ }^{[8]}$ motor neurone disease; ${ }^{[61]}$ patients with congenital heart disease, ${ }^{[11,12,18]}$ gastric illness, ${ }^{[13]}$ and elderly patients. ${ }^{[9,54]}$ is measurable; for example, cholesterol levels, blood pressure, body mass index and glucose levels which all give an overview of the condition of a patient's health. When treating health-related symptoms, clinicians may unwittingly be unaware of other symptoms seen as maybe irrelevant to health carers but could be distressing to a patient in the context of their lives. Vainio, ${ }^{[76]}$ notes that the choice of symptoms recorded depends on the purpose of 
the assessment: 'one can measure the most common symptoms, the most distressing, or the most treatable'.

Waldron et $\mathrm{al},{ }^{[20]}$ developed a modified SEIQoL-DW interview (that followed SEIQoL-DW interview) to assess patient nominated symptoms and related effects of these symptoms. Through a newly created semi-structured interview, during which the patients were asked to nominate the 5 worst symptoms they perceived in the preceding 2 weeks, then they were asked to display the 'relative' symptom bother (SB) of each of the symptoms to one another, using the 5 coloured interlocking SEIQoL-DW disc (each symptom nominated a 'colour'); then they were asked to consider (in the context of their QoL just discussed) to assess the interference of these symptoms with their QoL (SBIQoL), using a 2 coloured interlocking SEIQoL-DW disc with SB nominated 1 colour, QoL the other colour, the greater the space allocated to the symptom colour indicating the greater interference in their QoL. Therefore symptoms, their relative bother factor AND their interference with QoL was measured based on the definition that all symptom issues are 'what the patient deems them to be'. ${ }^{[15,16-19,-22,72,73]}$

This methodology proved to be very well understood by patients in studies referenced completed over the last two decades and was acceptable to patients. The 'info-graph' displayed below in Figures 3 and 4 show the immediate outline of the individual patient's concerns to empower targeted therapy to address these concerns. McInerney et $\mathrm{al}^{[14,15]}$ report a difference of $47 \%$ in SBIQoL in an active group of cancer patients in an acute hospital setting who had their 'info-graph' placed in the patient notes for their team's attention versus a control group who did not have 'info-graph' given to their team. The simple use of a picture of patient concerns as a 'clinical tool' made a highly significant difference to improve SBIQoL. As with QoL, patients should be involved in expressing their own most bothersome symptoms, not simply a pre-determined check-list of symptoms. Although patients may present with symptoms, these may or may not be bothersome. Waldron et $\mathrm{al},{ }^{[15,16,19-22,72]}$ when initiating the first SEIQoL/SEIQoL-DW study of palliative care patients, felt that there was an opportunity to 'link' symptoms and their bother factor to the SEIQoL style interview. The methodology developed has a flowing assessment of QoL with SEIQoL/SEIQoL-DW first, then patient nominated symptoms second, followed by the patient deciding the relative 'bother' of these symptoms (SB) together (if more than 1 symptom), finally a graphical patient directed measure of the 'interference' of these symptoms on their overall SQoL. Many published studies later highlight novel and illuminating results. ${ }^{[15,16,19-22,72]}$

\section{What Matters in Life Can Change - Response Shift:}

The subjective, dynamic nature of QoL creates significant difficulties for its' measurement and research in this area has produced a number of apparently contradictory findings. The expected deterioration in QoL often does not occur even in the case of serious illnesses, and indeed serious illness has been found to result in an increase in reported patient satisfaction and QoL. ${ }^{[3-6,9-}$ 18,22,41,62-64,66,67] The concept of adaptation brings into question the stability of the baseline of QoL perception over time. ${ }^{[61]}$ Based on a biomedical model of disease, it is often assumed that QoL invariably deteriorates as death approaches and yet that has not been borne out in practice. There is evidence that patients shift their focus from physical deterioration to other issues of relevance to their QoL in the face of inevitable death. There appears to be a process of psychological adaptation that enables patients cope and maintain good QoL, even in the face of adversity. Herein lies a vital methodological problem with longitudinal QoL research. There is an assumption when a research design is appropriately constructed that valid conclusions can be drawn from the relationship between the variables being examined. When $\mathrm{QoL}$ is assessed, by asking the same questions, at time one, time two, time three, there is a presumption that a subject's internalised standard of measurement is stable and will not change over time. In other words, a common metric exists between each scoring. However, in clinical practice this does not appear to be the case, as patients appear to adjust to their circumstances and in essence their internal frame of reference appears to recalibrate. This change or recalibration has been discussed in terms of RS. In the area of QoL research RS has been formally tested by asking a patient, at follow up assessments, after completing their assessment (the-then-test) at follow up attendances. Sprangers et $a 1,{ }^{[64]}$ examined for possible 'RS' in a group of patients undergoing radiotherapy by getting the patients at a post treatment assessment to first report how they perceive themselves at present (conventional post-test) then patients were asked to fill out the same measure in reference to how they perceive themselves to have been prior to the intervention, the 'then-test', but the study had a number of limitations hindering conclusions.

Traditionally changes in QoL are measured by an initial (pre-test) measurement, followed by a final (post-test) measurement after a set time period. It is argued that in this time the patient exposed to an extreme experience (e.g. advancing malignancy) undergoes a RS. This is defined as a change in the meaning of one's self-evaluation of QoL as a result of: (a) a change in the respondent's internal standards of measurement (recalibration); (b) a change in the respondent's values; or (c) a redefinition of life quality (reconceptualisation). In practical terms this theory suggests that the pre and post-test measurements are not on the same scale, thus threatening the validity of studies using this technique.

The concept of RS is not new. It was first described in 1979 by Howard et al, ${ }^{[6]}$ in the field of educational assessment. To correct for RS Howard, suggested the use of a retrospective pretest, or then-test. The initial pre-test is carried out as normal, but at the time of the post-test the subjects also complete a questionnaire relating to how they perceive themselves to have been at the time of the pre-test. The assumption is therefore that the subject will use the same criteria for the conventional post-test and the then rating. If the under-reporting of psychological complaints alluded to earlier is a consequence of RS, it is to be expected that the complaint level of the then-test will be much lower than of the post-test. It might also be lower than the complaint level reported by normal (control) subjects of the then-test. Subtracting the thentest (cancer patients) from the post-test (cancer patients) will indicate the real increase of complaints under the influence of the cancer. Subtracting the pre-test from the then-test in both cancer patients and controls allows calculation of the degree of RS.

Waldron et $\mathrm{al},{ }^{[5]}$ reports that little is known about the psychological adaptation that seems to take place for some people facing inevitable death, whereby many shift their focus from physical deterioration to other issues relevant to their QoL. There is so much we need to understand about how QoL/SB is cognitively constructed and maintained by people in adapting to changing circumstances, particularly in the face of chronic progressive diseases. ${ }^{[77]}$ Published studies confirm this finding and it is further enhanced with the incorporation of Response Shift (RS) into QoL studies. RS involves incorporating 'memory' at repeated QoL/Symptom assessments as well as the traditional pre-test and post-test measurements. How we 'feel' today is based on how we 
'remember' the past. All subjective outcome measurements have the potential for adaptation/reconceptualization i,e, RS. Waldron et $\mathrm{al},{ }^{[5]}$ prospectively assessed 80 consecutive patients with advanced incurable cancer and aware of the nature of their disease and found that QoL for most patients did not decrease as death approached, but in fact remained the same or for some improved. Mannion et $\mathrm{al},{ }^{[10]}$ found a clinically significant improvement in QoL in a group of patients with lung cancer when RS, the 'then-test' was incorporated into the QoL results. Most patients remember their QoL in the past as worse on the timing of repeat assessments. Rees et al, ${ }^{[73-75]}$ found similar results in a group of patients with prostate cancer and he also demonstrated a RS in symptoms using the modified SEIQoL-DW interview technique developed by Waldron et al. ${ }^{[5,10,15,16,20,72-75]}$ Indeed, for the majority of Physicians, who are not working directly with patients with inexorable deterioration in their health, the 'view' is that SQoL naturally deteriorates. This is not what Physicians in palliative care witness, as the majority of patients are in good form and do appear to have the capacity to 'harness' good despite their deteriorating health.

\section{Study Design and Participants:}

A cross sectional study design using an interview-based instrument of a random sample of members of the Cardiac Support Group ( $n=284)$ was employed. A cross sectional study design is suitable for descriptive and bi-variate analysis of data in terms of QoL, SB, and SBIQoL of individuals, at a particular point in time. As it was a once off assessment RS could not be addressed but is planned for future studies in this patient group.

\section{Methodology}

A mixed methods methodology was employed. ${ }^{[78]}$ SEIQoL-DW, patient symptom nomination, patient SB assessment and patient view of SBIQoL were assessed on one occasion in consecutive patients attending the cardiac rehabilitation clinic. The quantitative element permitted calculation of a global QoL index score, relative $\mathrm{SB}$, and the degree of SBIQoL. The qualitative element allowed for the collection of subjective experiences. A 'critical incident technique' was used to gather information, 'in the patient's words' one word or a sentence, that described their view experienced from their Cardiac event. ${ }^{[79]}$

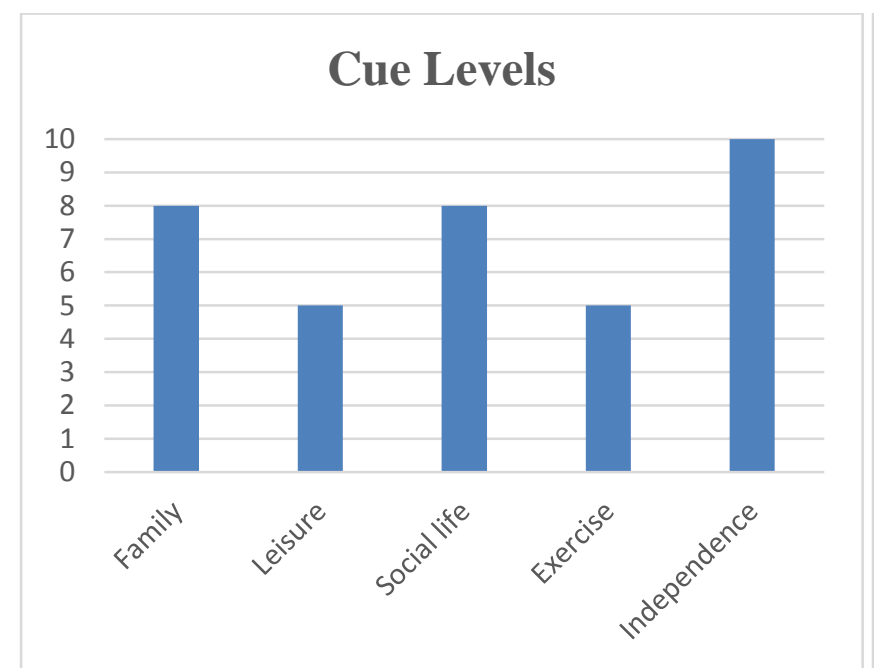

Step 1: Participants stated cues/domains of importance to their QoL were rated by the current level of functioning on a scale between 0-100, presented on a bar graph. Step 2: For the Direct Weighting procedure consisted of a disk containing five individually coloured segments representing the five life areas (cues) nominated by the individual. The participant is asked to 'weight' each cue using the disk by giving greater space to cues of most relative importance and less space to areas with less relative importance. The coloured segments can be adjusted and re-adjusted until the

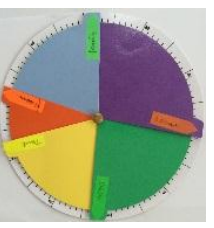
individual is satisfied that the proportion of the pie chart given to each life area Figure 1: SIEQoL-DW accurately reflects their perception of the relative importance (weights) contributing to their overall SQoL. Step 3: The overall SEIQoL-DW score, calculated out of 100 (best SQoL) reflected on a visual analogue scale (VAS). Step 4: Participant nominates the worst symptoms for him/her in the previous week. If more than five symptoms were nominated, then the patient was asked to nominate the five worst. Step 5: Assessment of participants perception of 'symptom interference' with overall SBIQoL. Participants were presented with the same SEIQoL disk modified to display two overlapping colours; one reflecting overall QoL and the other representing the patients view of the degree of SBIQoL in the past month. By using the two segments on the SEIQoL-DW disk, participants could indicate the degree to which the combined symptoms interfered with their QoL.

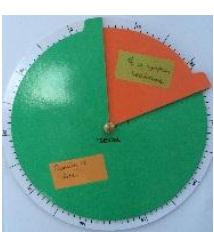

Figure 2: SIQoL
To ensure the SEIQoL-DW disk was fit for purpose, extensive piloting was necessary to hone the interviewer's skills and gain feedback from participants which highlighted areas where changes were required. The main goal of the pilot was to assess participants understanding of the research instrument and to ensure that it functioned optimally. ${ }^{[85]}$ Waldron et al, ${ }^{[5,14-16]}$ developed the first application of a modified SEIQoL-DW to assess symptom nomination, SB and SBIQoL and it was found to be acceptable, valid scientifically and sensitive to evaluate interventions. Both patient and professional proxy outcomes were assessed and the outcome measured the dynamic change in proxy assessments as they adapted to an awareness of their patient's 'true' concerns.

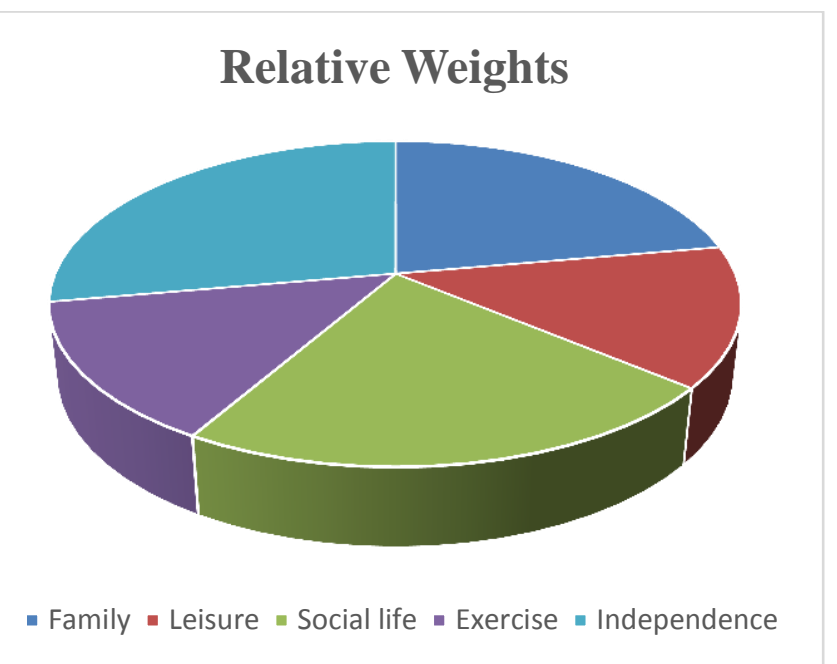

Global SEIQoL-DW Score $=82.70 \%$

Existing Bothersome Symptoms

Fear of Tiredness e.g. while driving

Medical Profession not listening

Numbness in hand. 


\section{Symptom Interference with QoL}

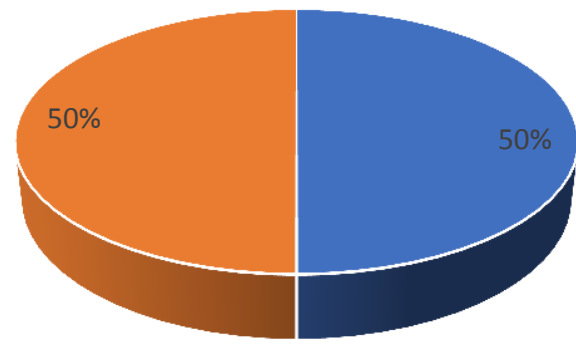

- QoL $\quad$ Symptom Interference

\section{Figure 3: Female aged 77 with cardiac condition}
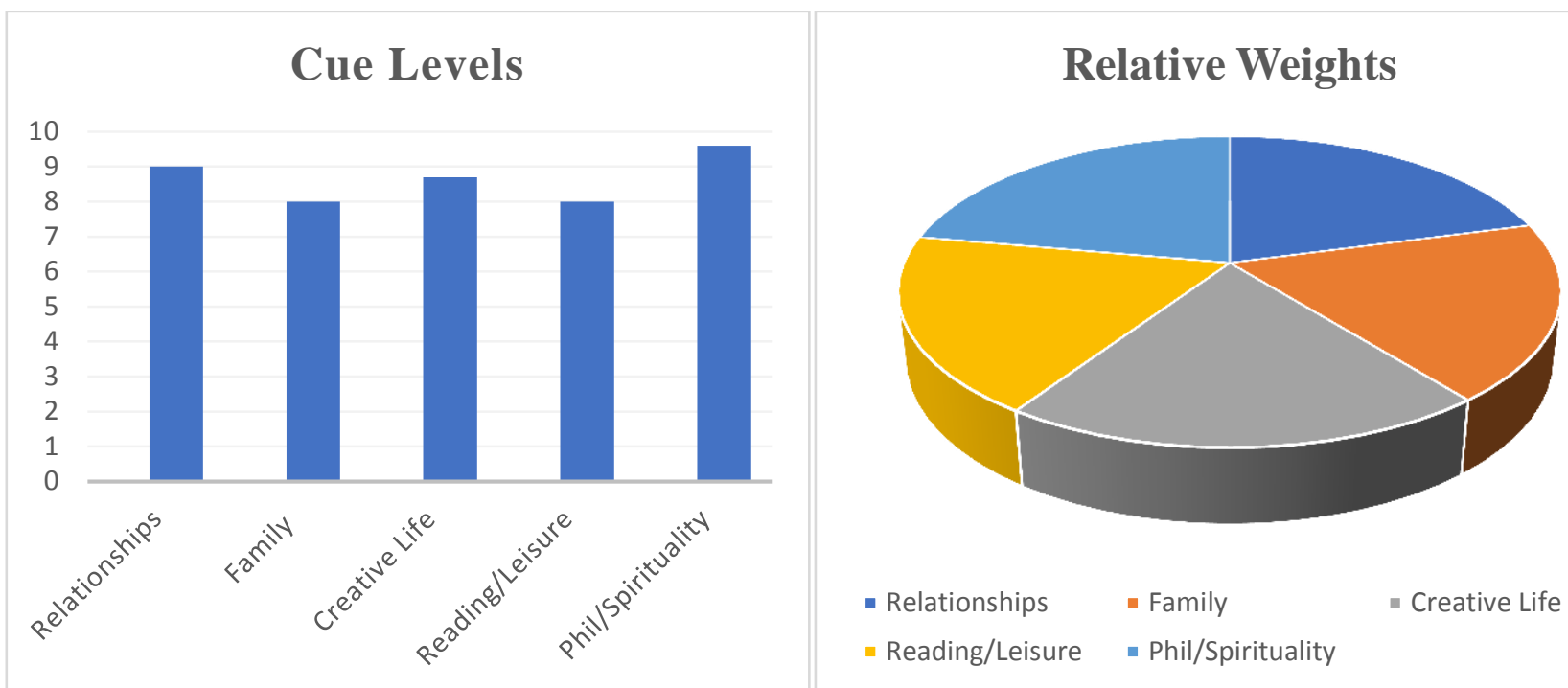

Global SEIQoL-DW Score $=88.85 \%$

\section{Existing Bothersome Symptoms}

Erectile Anxiety

Quick to Temper

Recall in terms of short-term-memory

Bladder problems at night

Night sweats

\section{Symptom Interference with QoL}

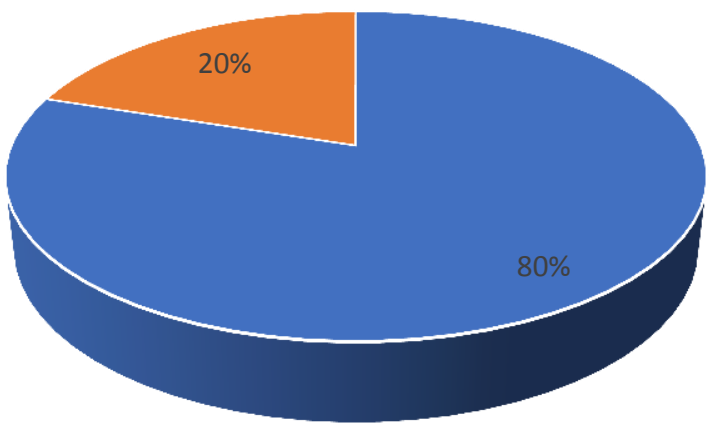

- Quality of Life $\quad$ Symptom Interference 
Figures 3\&4 above highlights together the QoL 'cues', SB, and SBIQoL unique to these individuals. While nominating SB, patients gave their view of the meaning of SB and this was gathered as the 'critical incident', a summary overview in the patient's words of the meaning of the SB. While there appears to be commonality in QoL 'cues' e.g. Family, Social/Relationships; this is in contrast to SB where in Table 3 for instance, a 77-yearold lady suffers from sudden acute tiredness leading to a fear of falling asleep while driving, numbness in her hand and a perception that she is not listened to by her medical professional. A Male aged 65 in Table 4 suffers from erectile anxiety, quickness to temper, poor recall in short-term memory, night sweats and bladder problems. Both patient's SB presentations are quite unique; the measurement of SBIQoL is also distinctively different for both patients, with the lady reflecting, 50\% SBIQoL and the male much lower at, $20 \%$. For those with high SBIQoL such a reading would give an immediate indication to the clinician that SB needs to be addressed with some urgency. 'Critical incidence' is outlined in Table 5 and discussed in 'discussion' section.

\section{Sample Frame and Strategy:}

Theoretically, this study has a population of 284 individuals who have self-selected to be part of a Cardiac Support Group (CSG), post event. Selecting a smaller proportion of the participants was deemed suitable to facilitate collection of more in-depth data. Access to the population of interest was granted by the management of 'Croi.', The heart and stroke prevention service in the West of Ireland. Members (sample units) of the Cardiac Support Group ( $n=284$ ), are not a random sample of the cardiac population in Co. Mayo, Ireland but rather a non-probability sample. Ideally, a purposive sampling technique allowing for maximum variation in terms of demographics would have been preferred for this study. However, as gender was the only known demographic; and to facilitate the introduction of some systematic process procedure into the selection of the study sample; data were divided into two numbered excel spread-sheets, 199 males and 85 females. 30 potential participants were randomly selected from each group using the computer application 'Random.Org' giving a total sample of 60 units. Hence, an element of probability sampling was introduced as each unit has a greater than zero chance of selection. In this study females had a higher chance of selection $(35 \%)$ than males $(15 \%)$. Importantly, random sampling controls for selection bias. A new excel data base was compiled containing 60 potential participants (30 males and 30 females) all of whom received a research pack inviting them to participate in the study.

\section{Analysis of Data:}

Data analysis and statistical analysis were executed in this study using SPSS 22, a statistical package used in the social sciences. The objectives of the study along with the variables elicited, determined the type of statistical analysis performed. In this regard the researcher used:

- Univariate analysis (descriptive statistics, using frequencies to determine measures of central tendency for the analysis of one variable) e.g. age, gender, type of condition, length since cardiac event and so on.

- Bivariate analysis (descriptive statistics for the analysis of the association between two variables) e.g. Independent t-test, Chi Squared; Fishers exact; Spearman's rho t-tests were utilized, and outcomes reported.

- Multivariate analysis was carried out, by comparing other study groups on whom SEIQoL-DW had previously been tested with results of this cardiac population.

\section{Perceptions of participants:}

Qualitative data was collected to profile participants of a cardiac support group. The process revealed rich qualitative data which gave an insight into salient QoL areas and nominated symptoms that impacted on participants' QoL. Their narratives revealed the unique nature of $\mathrm{QoL}$ and is further discussed in the results section.

\section{Results}

The demographic profile of sample: mean age; 69 ; males $64 \%$; females $36 \%$. Results demonstrated six categories of events; heart attack $32 \%$, stroke $4.5 \%$, Stents/Angioplasty $41 \%$, Bypass $9 \%$, Aortic Root Repair 4.5\%, Heart-Valve Surgery 9\%. The modal length of time since the event was $25-36 \mathrm{mths}$. $64 \%$ were retired; a total of $68 \%$ had attended cardiac rehabilitation with $23 \%$ yet to attend and $9 \%$ not attending.

\section{SEIQoL-DW Scores and Symptom Results:}

- The mean Global SEIQoL-DW Index Score was $81.60 \%$ with a range of between, $41.19 \%-100 \%$.

- A total of 21 different QoL cue categories were nominated with family and leisure pursuits nominated in $95 \%$ and $91 \%$ of cases respectively.

- $45 \%$ of participants did not rate 'health' in the first five of their chosen QoL cues

- A significant number experienced symptoms, 68\%;

- The degree of SBIQoL varied from 'no interference' to as high as $85 \%$ interference.

- A significant negative correlation was found between SBIQoL and QoL, rho=-0.353 with high levels of SIBQoL associated with low levels of QoL.

- The relevance of gathering data around nominated symptoms is evidenced by the number of participants that experienced symptoms (68\%).

- Diversity of QoL and SBIQoL are presented in Tables $2 \& 3$ below.

- A critical incident technique was used to gather information, 'in the patient's words' one word or a sentence, that described the experience of their Cardiac event. Results outlined in Table 4 below and further elucidation of their commentary analysed in the discussion. Their narratives were divided into three symptom categories: Cognitive, Physical and Psychological symptoms.

Table 2: Top 10 QoL Cues nominated by a Cardiac Population

\begin{tabular}{|l|c|c|}
\hline Elicited Cues & Frequency & Percentage \\
\hline Family & 21 & $95 \%$ \\
\hline Leisure Pursuits & 20 & $91 \%$ \\
\hline Social Aspects of Life & 12 & $55 \%$ \\
\hline Health & 12 & $55 \%$ \\
\hline Relationships & 8 & $36 \%$ \\
\hline Work & 6 & $27 \%$ \\
\hline Spirituality/Religion & 6 & $27 \%$ \\
\hline Happiness & 4 & $18 \%$ \\
\hline Social Support & 3 & $14 \%$ \\
\hline Financial & 3 & $14 \%$ \\
\hline
\end{tabular}

Table 3: Top 10 Symptoms nominated by a Cardiac Population

\begin{tabular}{|l|l|l|}
\hline Elicited cues & Frequency & Percentage \\
\hline Sudden Tiredness & 5 & $26 \%$ \\
\hline Anxiety & 3 & $16 \%$ \\
\hline Quick to Temper & 2 & $11 \%$ \\
\hline Erectile Anxiety & 2 & $11 \%$ \\
\hline
\end{tabular}




\begin{tabular}{|l|l|l|}
\hline Bladder problems at night & 2 & $11 \%$ \\
\hline Losing power in the hand & 2 & $11 \%$ \\
\hline Worry of Infection & 2 & $11 \%$ \\
\hline Knowing exercise limits & 2 & $11 \%$ \\
\hline Grogginess & 2 & $11 \%$ \\
\hline Breathlessness & 2 & $11 \%$ \\
\hline
\end{tabular}

Table 4: Participants Narratives: 'Critical Incident Technique':

A male, 65, describes cognitive symptoms experienced after his cardiac event:

The doctor told me to expect loss of memory, well loss of short term memory....you know because of the procedure I had......that bothers me....the other day I couldn't think of the words to the Leonard Coen song - 'So Long, Marianne' - of course I remember them now...... but at the time it bothered me.

Male aged 60:

Guilt that I am still alive.... when I go to the funerals of others younger than me.

A female, 55, describes physical symptoms:

Dr. (X) told me that I had suffered quite a trauma....he says that my chest received a pounding......I suffer muscular pain here (rubbing her chest)......I suffer from claustrophobia.... when in a large crowd.... which I try to avoid.....but when my father died in March this year, people came to the house and I could feel my heart racing....like I suppose a panic attack.

A male, 65:

Well.....going to the toilet during the night......I know the diuretic affects me that way.......but it's affecting my sleep if you like...... and my partners sleep.

A male, 70, describes his psychological anxiety:

You know I attend two doctors and I would really like to know how much exercise is too much, I mean I could be out working in the garden or on top of the roof.......I spent a lot of my time as a carpenter......... and the neighbours going by say to me that I shouldn't be at those jobs; very bad for a man with a heart condition. It really gets to me and I'd like to know how far I can go when exercising

A male, 65, describes his thoughts around what makes him anxious:

I have a fear that the medication will make me impotent........I worry that it will affect my wonderful relationship...... I suppose you could call it erectile anxiety. I worry about my short temper......my partner would say I always had a short temper (laugh)...but I wonder is it the medication?

\section{Discussion}

A limitation of this study is the small number of participants $(n=22)$. However, each interviewee was given the time and space necessary to put forward their QoL cues, evaluate their SB and SBIQoL. The diversity of SEIQoL-DW enabled their QoL to be measured as an outcome and a performance indicator, as an $n=1$ type study and was found to be acceptable and valid to this cardiac population. This may well be attributable to the person-centred application of SEIQoL-DW, which affords a unique perspective on life and QoL of each individual. As a communication aide SEIQoL-DW engaged participants, particularly men who were eager to participate and talked candidly about issues that were important to them. The SEIQoL-DW score was very high compared to other sick patient populations and their mean score was similar to the healthy elderly population studied with SEIQoLDW. The most frequently nominated cues elicited by participants were similar to those nominated in other published SEIQoL studies. These QoL cues raise a number of important issues in relation to the health and wellbeing of this population. It is often assumed that health status is the primary conceptual QoL concern for patients with chronic health conditions however, these participants revealed many other issues of concern to their QoL with $45 \%$ of respondents not rating 'health' in their first five most important cues. Waldron et $\mathrm{al}^{[5]}$ showed that in assessing individual QoL in a group of patients with advanced cancer, health was not the single most important area to this patient group; patients consistently gave higher weightings to family. There is a sense that cardiac rehabilitation patients may 'let go' of what can't be controlled, i.e., 'Health' and focus on 'Other' issues of importance to their SQoL.

Paradoxically, despite finding an inverse relationship between QoL and symptom interference, some participants reported high QoL scores but also relatively high degrees of symptom interference; this may suggest that individuals are coping well with the level of symptoms interference. We, as human beings, base how we 'feel today' on our reflection of how we felt at a previous time point. Despite all of these participants experiencing a cardiac event and varying degrees of deterioration in their physical health, they somehow were able to 'anchor' their perception of their QoL based on non-health related parameters. Given the opportunity to express themselves these participants were able to maintain good spirits and harness good in the situation they find themselves in. A 74 year old lady for instance, focused on the benefit gleaned from adaptations made to her home/person rather than her deteriorating health. 'The grab rails in the shower and the kitchen were really great - excellent - and also the alarm buttons, especially the one around your neck, you're always safe and they check them every month.' It would appear that the human spirit has an innate potential to 'let go' of physical deterioration that is beyond their control and not only cope with, but create deeper 'meaning' in their lives and somehow improve their QoL.

SEIQoL is essentially patient directed; the patient in essence, is presented with a 'blank page' and it is the patient that delivers the information that creates the 'graph' of their QoL. SEIQoL is developed based on the definition of QoL as 'what the patient says it is'. SEIQoL completed using the JA methodology gives strong scientific validity to this study. SEIQoL-DW is 'userfriendly', it takes on average ten minutes, therefore, 'time' is short to complete this validated interview. ${ }^{[19]}$ SEIQoL using JA is considered to assess 'unconscious' thought and SEIQoL-DW more 'conscious' thought, therefore SEIQoL-DW is more relevant to the 'clinical' scenario. ${ }^{[5]}$ SEIQoL and SEIQoL-DW generates a 'graphical' image of the patient's QoL. This makes it amenable for clinicians to understand. Clinicians are used to interpreting 'graphs' and 'trends'; charts are kept at the patient's bedside usually with temperature, blood pressure, heart rate and respiratory rate (TPR chart). Clinicians 'view' this TPR chart and gain an immediate understanding of the patient's 'vital signs' from which they formulate a management plan. McInerney et al, ${ }^{[15,16]}$ have completed a study using SEIQoL results incorporated into patient notes to test the hypothesis that using the knowledge of QoL as a clinical tool, improves the actual outcome of QoL and significantly reduces SBIQoL.

The experience of having heart failure can have a significant impact on every aspect of an individual's sense of wellbeing and thus his/her QoL. In evaluating the effectiveness of treatment regimens, it is important to capture this dimension to ensure individuals are offered appropriate care and support. Temel et $\mathrm{al}^{\left[{ }^{[60]}\right.}$ showed prolongation of life for a patient population with lung cancer by palliative care involvement from diagnosis, which raises an important question. Is this improved survival pivotal to enhanced awareness and action taken based on QoL issues? Based on this hypothesis, clinicians, have a duty to explore further what 
QoL means to patients, how each patient 'recalibrates and shifts' in their appreciation of QoL issues over the trajectory of their disease and 'how' QoL is measured in future studies. SEIQoL/ SEIQoLDW could be used to explore the hypothesis; that if clinicians are in tune with patient's perceived QoL issues, and how these issues may change as patient's adapt and reconceptualise their lives to what really matters throughout the trajectory of their cardiac condition; then maybe this knowledge could be a key factor in improved actual 'quality' and 'longevity' for a vulnerable patient group. ${ }^{[12]}$

In this study as patients initially talked about their SQoL, immediately followed by nominating SB, which they presented on a modified disk to reflect the relative 'Bother' of these symptoms, then using a 2 coloured disk they displayed graphically the degree to which these nominated symptoms interfered with their SQoL. These self-reported presentation led to interesting findings. The graphical image of the degree to which symptoms interfered with QoL had a highly significant impact on how clinicians addressed these symptoms in a controlled trial setting in oncology. McInerney et $\mathrm{al},{ }^{[15,16]}$ reported a $49 \%$ positive improvement in SQoL in an active group versus a control group in a controlled setting. ${ }^{[16]}$ These highly significant findings clarify that the 'graphs' were easy for clinicians to interpret and true to the patients concerns over time. A previous similar study in a Hospice did not show a significant difference in active or control and it could be argued that in a Hospice all focus is on symptom control and QoL. ${ }^{[83]}$ The gathering of such patient-orientated information in the acute hospital setting in the future could yield positive results and become a relatively easy and speedy way to gather such invaluable patient views. This could be a way to target interventions in the right direction for symptomatic patients.

The individual 'critical incident' comments in Figure 4, enable us to examine concerns that go well beyond the patient's 'vital signs', encompassing cognitive, physical and psychological issues as expressed by the patient. A 65-year-old male describes loss of memory, and while his clinician correctly told him to expect same after his cardiac surgery; the patient's concern was he had no timeframe to anticipate return to normal cognitive functioning. A 55-year-old lady describes her physical symptoms in terms of contusion from capillary damage caused by trauma "he says that my chest received a pounding." This female developed claustrophobia, which presented physically by way of tachycardia and panic attacks. Her expectation was that this was something she would have to live with; she therefore avoids large crowds. At her father's funeral, she experienced physical symptoms described in her narrative above; she did not talk of strategies to overcome signs and symptoms. Targeted psychotherapy could be helpful in this scenario. A 65-year-old male describes his psychological symptoms, he worries that his medication will make him impotent and negatively affect his wonderful relationship with his wife. A 62-year-old man describes his experience of impotence as a result of his medication. He describes himself as "happily married.. I'd say in all our years of marriage, I could count on one hand (holds out his right hand)....I mean we never fight...." He says that his clinician had reduced his medication to a minimum amount, but that he is still experiencing adverse effects. A 77-year-old female describes physical symptoms of acute tiredness; she has a fear of falling asleep while driving. Further, she experienced numbness in her hand and felt that the "medical profession were not listening" to her concerns. Symptoms arising that are cardiac in nature should be addressed by the cardiology team and non-cardiac symptoms nominated, gives the opportunity to cardiology team to act as 'gatekeepers' for their patients by referring them to specialists who can deal with these symptoms.

Though RS is not addressed in this research; a prospective study like this in larger numbers, inclusive of RS as an outcome measure could have implications for the effectiveness of interventions. A future clinical trial, with SEIQoL, SB, SBIQoL and RS outcome results fed back (active group) to the multidisciplinary team looking after cardiac rehabilitation patients and not fed back (control group). Such a study would further enhance knowledge of individual's concerns, symptoms and how they are coping. McInerney et al, ${ }^{[15,16]}$ reported highly significant reduction in SBIQoL in a group of patients with cancer. When patients in this study nominated symptoms that bothered them, as indicated in Table 3; interestingly, the SB of 'breathlessness' was only nominated by $11 \%$. Other symptoms that were rated with a higher degree of interference were; 'sudden tiredness' which could be addressed by structured exercise and other achievable interventions; anxiety could be addressed with extra psychological support; erectile dysfunction and other issues could be amenable to medical intervention. This simple methodology of asking the patients about the bother factor of their symptoms highlights interesting results and has been born out in similar SIEQoL studies addressing SB. ${ }^{[20-22]}$ Many decades ago Tywcross, ${ }^{[77]}$ discussed the 'troublesomeness' of symptoms as the missing factor in symptom assessment, this and other published work confirms his concern.

The 'blank page' method of SEIQoL could have a role, in future studies to 'select out' patients that need more in-depth exploration (unconscious thought) of the underpinning of their QoL issues, i.e. for legal documents, patient's having difficulties making informed decisions regarding treatment options. The simpler SEIQoL-DW takes an average of ten minutes to complete, is patient friendly and would appear to be accurately interpreted by clinicians. Murtagh et $\mathrm{al},{ }^{[81]}$ highlights the acceptability of SEIQoL-DW for first year medical students on a 'Special Study Module' called 'Introducing the Medical Student to the 'person' not the 'patient'. In general, medical students found the process of the SEIQoL-DW, acceptable and felt they 'knew' the patient better after preforming the SEIQoL-DW interview with them.

Failure by health professionals to understand the complex nature of individual QoL could result in treatment regimens that not only fail to improve QoL but actually contribute to its deterioration. Modern approaches to patient treatment increasingly recognise the importance of incorporating the views of patients in treatment planning. Therefore, patients with advanced disease should be asked what they prioritize in their lives. Based on a biomedical model of disease, it is often assumed that QoL invariably deteriorates with advancing disease. However, in clinical practice there is evidence that patients may undergo a psychological adaptation to their illness and shift the focus of QoL judgments from physical deterioration to spiritual, psychological and social domains. This ability to adapt to changing circumstances is a defining characteristic of human beings, and illustrates the resilience and extraordinary vitality of the human spirit.

For Cardiac rehabilitation patients already attending excellent on-going Cardiac rehabilitation clinics, consideration of on-going 'interviews' akin to the SEIQoL could unearth surprising information to direct clinicians in a direction that is totally patientfocused and the 'interview' is usually considered enjoyable to the patient. The importance of the 'relationship' with the interviewer is also worthy of future study, as is the satisfaction of being interviewed face-to face rather than filling in a box from a predetermined questionnaire. Temel et al, ${ }^{[60]}$ created a paradigm shift by scientifically showing that palliative care involvement for 
terminally ill lung cancer patients from diagnosis, improved patient survival. Giving credence and value to cardiac rehabilitation patients personal, subjective views on their QoL, as well as understanding their re-evaluation of their QoL could require a similar shift.

In summary, the eloquent description of happiness by Author Amoz Oz is enlightening; "whereas happiness is a rare, fine vessel, a sort of Chinese vase, and the few people who have reached it have shaped and formed it line by line over the course of years, each in his own image and likeness, each in his own character, so that no two happinesses are alike. In the moulding of their happiness they have instilled their own suffering and humiliation. Like refining gold from ore. ${ }^{[83]}$

\section{Acknowledgement}

Neil Johnson CEO, CROÍ, The West of Ireland Cardiac \& Stroke Foundation and the National Institute for Prevention and Cardiovascular Health, Galway, Ireland.

\section{References}

[1] Joyce CRB, et al. doi:10.1023/A:1023273117040. "A Theory-Based Method for the Evaluation of Individual Quality of Life: The SEIQoL." [updated 2003. pp. 27580].

[2] O'Boyle CA, McGee H, Hickey A, O'Malley K, Joyce CR. Individual quality of life in patients undergoing hip replacement. Lancet (London, England). 1992;339(8801):1088-91.

[3] O'Boyle CA, Waldron D. Quality of life issues in palliative medicine. Journal of Neurology. 1997;244(4):S18-S25.

[4] Waldron D, O'Boyle, C. A. Individual Quality of Life in Palliative Care. In: Joyce CR, O'Boyle, C. A., McGee, H., editor. Individual Quality of Life: Approaches to Conceptualisation and Assessment.

[5] Waldron D, O'Boyle, C. A., Kearney, M., Moriarty, M., \& Carney, D. Quality-of-life measurement in advanced cancer: Assessing the individual. Journal of Clinical Oncology. 1999;17(11):3603-11.

[6] Hickey AM, Bury, G., O'Boyle, C.A., Bradley, F., O'Kelly, F.D., et al. A new short form individual quality of life measure (SEIQoL-DW): application in a cohort of individuals with HIV/AIDS. British Medical Journal Publishing Group. 1996;313(7048):29.

[7] Lhussier M, Watson B, Reed J, Clarke CL. The SEIQoL and functional status: how do they relate? Scandinavian Journal of Caring Sciences. 2005;19(4):403-9.

[8] Lintern TC, Beaumont JG, Kenealy PM, Murrell RC. Quality of Life (QoL) in severely disabled multiple sclerosis patients: Comparison of three QoL measures using multidimensional scaling. Quality of Life Research. 2001;10(4):371-8.

[9] Mannion E, Gilmartin J, Donnellan P, Keane M, Waldron D. Effect of chemotherapy on quality of life in patients with non-small cell lung cancer. Supportive Care in Cancer. 2014;22(5):1417-28.

[10] Mannion E, Gilmartin JJ, McInerney V, Molony K, Basquille E, Waldron D. Exploring the Innate Human Potential for Positive Adaptation in the Face of Impending Mortality: Is there a Response Shift in Subjective Quality of Life over Time in a Group of
Patients with Lung Cancer Receiving Palliative Treatment? International Journal of Innovative Research in Medical Science. 2020;5(05):160 to 8- to 8 .

[11] McGee H. Health Related Quality of Life in Cardiac Patients. In: Perk J, editor. Cardiovascular Prevention and Rehabilitation. London: Springer; 2007.

[12] McGee H. Changing Cardiovascular Health. National Cardiovascular Health Policy 2010-2019. In: DoH\&C., editor. Dublin2019.

[13] McGee H. Assessing the Quality of Life of the Individual: the SEIQoL with a healthy and a gastroenterology unit population. Psychological medicine. 1991;21(3):749-59.

[14] McInerney V, Mannion, E., Waldron, D. Using Quality of Life Information as a Clinical Tool in Patients with Advanced Cancer. Journal of Clinical Oncology. 2015;33(29-suppl):91-91.

[15] McInerney E, Mannion, E., Moses, A., Molony, K., Waldron, D. A Guide to Selecting a Measurement Tool for Quality of Life Assessment. Medical and Clinical Research Journal. 2019;4(5):1-6.

[16] McInerney V, Mannion, E., Reilly, L., Molony, K., Waldron, D. An Intervention Using QoL and Symptom Information in a Clinical Tool in Patients with Advanced Cancer. International Journal of Innovative Research in Medical Science. 2019;4(8):517-24.

[17] Moons P, Budts W, De Geest S. Critique on the conceptualisation of quality of life: A review and evaluation of different conceptual approaches. International Journal of Nursing Studies. 2006;43(7):891-901.

[18] Moons P, Marquet K, Budts W, De Geest S. Validity, reliability and responsiveness of the "Schedule for the Evaluation of Individual Quality of Life - Direct Weighting" (SEIQoL-DW) in congenital heart disease. Health and Quality of Life Outcomes. 2004;2(1):27.

[19] O'Boyle C, Browne J, Hickey A, McGee H, Joyce C. The Schedule for the Evaluation of Individual Quality of Life (SEIQoL): a Direct Weighting procedure for Quality of Life Domains (SEIQoL-DW). Administration Manual. 1993.

[20] Waldron D. Quality of life and symptoms as judged by terminally ill patients and their professional carers. Journal of Palliative Medicine. 2002;Abstract 244.

[21] Waldron D, McInerney V, Mannion E. A Single Centre, Prospective, Randomised Controlled Trial of Using Subjective Quality of Life and Symptom Outcome Measures as a Clinical Tool, Reporting to the Multidisciplinary Team to Determine its Impact on the Subsequent Quality of Life and Symptoms Outcomes of Individual Patients with Cancer: Abstract number: MTE4 Abstract type: Meet-the-expert. Palliative Medicine. 2016;30(6).

[22] Waldron D, McInerney, V., Basquille, E., Molony, K., Mannion, E. An Exploratory Review of Subjective Quality of Life Measurement in Palliative Care: A Journey over Three Decades. "Examining Quality of Life as a Dynamic Construct”. In Press.

[23] Asadi-Lari M, Tamburini, M., Gray, D. Patients' needs, satisfaction, and health related quality of life: towards a comprehensive model. Health and Quality of Life Outcomes. 2004;2(32). 
[24] Bowling A. Measuring Health: A Review of Subjective Health, Well-being and Quality of Life Measurement Scales. Milton Keynes.: Open University Press; 2017.

[25] Campbell A, Converse, P. E., \& Rogers, W. L. The Quality of American Life: Perceptions, Evaluations and Satisfaction. New York: Russell Sage Foundation 1976.

[26] Campbell S, Whyte F. The quality of life of cancer patients participating in phase I clinical trials using SEIQoL-DW. Journal of Advanced Nursing. 1999;30(2):335-43.

[27] Coates A, Gebske, V., Bishop, J. F., Jeal, P. N. Improving the Quality of Life during Chemotherapy for Advanced Breast Cancer. New England Journal of Medicine. 1987;317:1490-5.

[28] Coen RF, O'Boyle, C. A., Coakley, D., Lawlor, B. A. Dementia Carer Education and Patient Behaviour Disturbance. International Journal of Geriatric Psychology. 1999;14(4):302-6.

[29] Cohen SR, Mount, B. M., Strobel, M. G., \& Bui, F. The McGill Quality of Life Questionnaire: a measure of quality of life appropriate for people with advanced disease. A preliminary study of validity and acceptability. Palliative Medicine. 1995;9(3):207.

[30] Dempster M, Donnelly, M. Measuring the HealthRelated Quality of Life of People with Ischaemic heart Disease. British Medical Journal 2000;86(6):641.

[31] Gilson BS, Gilson JS, Bergner M, Bobbit RA, Kressel S, Pollard WE, et al. The sickness impact profile. Development of an outcome measure of health care. Am J Public Health. 1975;65(12):1304-10.

[32] Greenhalgh J, Meadows K. The effectiveness of the use of patient-based measures of health in routine practice in improving the process and outcomes of patient care: a literature review. Journal of evaluation in clinical practice. 1999;5(4):401-16.

[33] Taylor RS, Brown A, Ebrahim S, Jolliffe J, Noorani H, Rees K, et al. Exercise-based rehabilitation for patients with coronary heart disease: systematic review and metaanalysis of randomized controlled trials. The American Journal of Medicine. 2004;116(10):682-92.

[34] Maloney K, Chaiken, B.P. An overview of outcomes research and measurement. Journal for Healthcare Quality. 1999;21(6):4-10.

[35] Szabo S. Quality of Life and Pharmacoeconomics in Clinical Trials. The World Health Organisation Quality of Life (WHOQoL) assessment instrument. 1996:355-62.

[36] Bowling A. Measuring Health: A Review of Subjective Health, Well-being and Quality of Life Measurement Scales. Milton Keynes.: Open University Press; 2017.

[37] Cella DF, Tulsky David S. Measuring Quality of Life today: methodological aspects. Oncology (Willliston Park, NY). 1990;4(5):29-38.

[38] Patrick DL, Erickson P. Assessing health-related quality of life for clinical decision-making. In: Walker SR, Rosser RM, editors. Quality of Life Assessment: Key Issues in the 1990s. Dordrecht: Springer Netherlands; 1993. p. 11-63.

[39] Kagawa-Singer M. Redefining health: Living with cancer. Social Science \& Medicine. 1993;37(3):295-304.

[40] Armstrong D. Public Health Spaces and the Fabrication of Identity. Sociology. 1993;27(3):393-410.

[41] Dempster M, Carney R, McClements R. Response shift in the assessment of quality of life among people attending cardiac rehabilitation. Br J Health Psychology. 2010;15(Pt 2):307-19.

[42] DoH. Healthy Ireland - A Framework for Improved Health and Wellbeing. In: Health Do, editor. Dublin2013.

[43] DoH. Healthy Ireland Survey. In: Health Do, editor. Dublin2015.

[44] DoH\&C. Changing Cardiovascular Health. Dublin: Government Publications; 2010.

[45] Wallwork J, Caine, N. A Comparison of the Quality of Life of Cardiac Transplant Patients and Coronary Artery Bypass Graft Patients Before and after Surgery. Quality of Life and Cardiovascualar Care. 1985;1(7):317-31.

[46] Welman JC, Kruger, F. Research Methodology for the Business and Administrative Sciences: Oxford University Press; 2001.

[47] Wenger NK, Mattson, M. E., Furberg, C. D., \& Elinson, J. Assessment of Quality of Life in Clinical Trials of Cardiobascular Therapies. The American journal of cardiology. 1984;54(7):908-13.

[48] WHO. Global Conferences on Health Promotion 1986 [Available from: https://www.who.int/healthpromotion/conferences/en/

[49] Whooley MA, de Jonge P, Vittinghoff E, Otte C, Moos R, Carney RM, et al. Depressive Symptoms, Health Behaviours, and Risk of Cardiovascular Events in Patients with Coronary Heart Disease. JAMA. 2008;300(20):2379-88.

[50] McEwen J. The Nottingham Health Profile. In: Walker SR, Rosser RM, editors. Quality of Life Assessment: Key Issues in the 1990s. Dordrecht: Springer Netherlands; 1993. p. 111-30.

[51] Loge JH, Kaasa S. Short form 36 (SF-36) health survey: normative data from the general Norwegian population. Scandinavian journal of social medicine. 1998;26(4):2508.

[52] Anderson C, Laubscher S, Burns R. Validation of the Short Form 36 (SF-36) health survey questionnaire among stroke patients. Stroke. 1996;27(10):1812-6.

[53] Bergner M, Bobbitt RA, Carter WB, Gilson BS. The Sickness Impact Profile: development and final revision of a health status measure. Medical care. 1981;19(8):787805.

[54] Smith HJ, Taylor R, Mitchell A. A comparison of four quality of life instruments in cardiac patients: SF-36, QLI, QLMI, and SEIQoL. Heart. 2000;84(4):390.

[55] Dougherty CM, Dewhurst T, Nichol WP, Spertus J. Comparison of three quality of life instruments in stable angina pectoris: Seattle Angina Questionnaire, Short Form Health Survey (SF-36), and Quality of Life IndexCardiac Version III. Journal of clinical epidemiology. 1998;51(7):569-75.

[56] Kao CW, Friedmann E, Thomas SA. Quality of life predicts one-year survival in patients with implantable cardioverter defibrillators. Quality of life research : an international journal of quality of life aspects of treatment, care and rehabilitation. 2010;19(3):307-15.

[57] Lundborg M, Wille S, Bjermer L, Tilling B, Lundgren M, Telg G, et al. Maintenance plus reliever budesonide/formoterol compared with a higher maintenance dose of budesonide/formoterol plus formoterol as reliever in asthma: An efficacy and cost- 
effectiveness study. Current medical research and opinion. 2006;22:809-21.

[58] Moulton B, King JS. Aligning Ethics with Medical Decision-Making: The Quest for Informed Patient Choice. The Journal of Law, Medicine \& Ethics. 2010;38(1):85-97.

[59] Sugarbaker PH, Barofsky I, Rosenberg SA, Gianola FJ. Quality of life assessment of patients in extremity sarcoma clinical trials. Surgery. 1982;91(1):17-23.

[60] Temel JS, Greer, J. A., Admane, S.,. Longitudinal Perceptions of Prognosis and Goals of Therapy in Patients with Metastatic Non-Small-Cell Lung Cancer: Results of a randomized study of early palliative care. Journal of Clinical Oncology. 2011.

[61] Neudert C, Wasner M, Borasio GD. Individual quality of life is not correlated with health-related quality of life or physical function in patients with amyotrophic lateral sclerosis. J Palliat Med. 2004;7(4):551-7.

[62] Sprangers MA, Schwartz CE. Integrating response shift into health-related quality of life research: a theoretical model. Social science \& medicine (1982). 1999;48(11):1507-15.

[63] Schwartz CE, Bode R, Repucci N, Becker J, Sprangers MAG, Fayers PM. The clinical significance of adaptation to changing health: A meta-analysis of response shift. Quality of Life Research. 2006;15(9):1533-50.

[64] Mirjam AG Sprangers, Frits SAM Van Dam, Jenny Broersen, Litanja Lodder, Lidwina Wever, Mechteld RM Visser, Paul Oosterveld, Ellen MA Smets, Mirjam. "Revealing response shift in longitudinal research on fatigue: the use of the thentest approach." Acta Oncologica 38.6 (1999): 709-718.

[65] Donabedian A. THE METHODS AND FINDINGS OF QUALITY ASSESSMENT AND MONITORING: AN ILLUSTRATED ANALYSIS. The Journal for Healthcare Quality (JHQ). 1985;7(3):15.

[66] Howard GS, Dailey PR. Response-shift bias: A source of contamination of self-report measures. Journal of Applied Psychology. 1979;64(2):144.

[67] Bernhard J, Lowy A, Maibach R, Hürny C, Research SGfCC, Research SIfAC. Response shift in the perception of health for utility evaluation: an explorative investigation. European Journal of Cancer. 2001;37(14):1729-35.

[68] Calman KC. Quality of Life in Cancer Patients - an hypothesis. Journal of Medical Ethics. 1984;10(3):124.

[69] Raphael D, Brown, I., Renwich, R., Cava, M., Weir, N., Heathcote, K. The Quality of Life of Seniors Living in the Community: a Conceptualisation with Implications for Public Heath Practice. Canadian Journal of Public Health/Revue Canadienne de Sante'e Publique. 1995;86(4):228-33.
[70] Wolfensberger W. Let's hang up 'Quality of Life' as a hopeless term. Cambridge, MA: Brookline Books; 1994. 285-321 p.

[71] Häyry M. Individual Quality of Life; Approaches to Conceptualisation and Assessment. East Sussex: Routledge; 1999.

[72] Pearcy R, Waldron D, O'Boyle C, MacDonagh R. Proxy assessment of quality of life in patients with prostate cancer: how accurate are partners and urologists? J R Soc Med. 2008;101(3):133-8

[73] Rees J, Waldron D, O'Boyle C, Ewings P, MacDonagh R. Prospective vs retrospective assessment of lower urinary tract symptoms in patients with advanced prostate cancer: the effect of 'response shift'. BJU International. 2003;92(7):703-6.

[74] Rees J, Clarke MG, Waldron D, O'Boyle C, Ewings P, MacDonagh RP. The measurement of response shift in patients with advanced prostate cancer and their partners. Health and Quality of Life Outcomes. 2005;3(1):21.

[75] Rees J, Waldron D, Amp, Apos, Boyle C, Macdonagh R. Response shift in individualized quality of life in patients with advanced prostate cancer. Clinical Therapeutics. 2002;24:33-4.

[76] Vainio A, Auvinen A. Prevalence of symptoms among patients with advanced cancer: An international collaborative study. Journal of Pain and Symptom Management. 1996;12(1):3-10.

[77] Twycross R, Wilcock, A. Symptom management in advanced cancer. 3rd ed. Oxford: Radcliffe Publishing; 2001.

[78] Welman JC, Kruger, F. Research Methodology for the Business and Administrative Sciences: Oxford University Press; 2001.

[79] Butterfield L, Borgen W, Amundson N, Maglio A-S. Fifty Years of the Critical Incident Technique. Qualitative Research. 2005;5:475-97.

[80] Thabane L, Ma J, Chu R, Cheng J, Ismaila A, Rios LP, et al. A tutorial on pilot studies: the what, why and how. BMC Medical Research Methodology. 2010;10(1):1.

[81] Murtagh C, Flaherty, G., Mannion E., Waldron, D.,. End of Life Enhancement: A novel introduction of medical students to palliative medicine. . Journal of Palliative Medicine. 2012;15(9):965-6.

[82] Kelly S, Sheehan, P., Waldron D., editor A Single Centre, Prospective, Randomised Control Trial of Using Subjective Quality of Life and Symptom Outcome Measures as a Clinical Tool, reporting to the Multidisciplinary Team to Determine its Impact on the Subsequent Quality of Life and Symptoms Outcomes of Individual Patients with Cancer in a Hospice setting. . Marie Curie Study Day; 2002; London.

[83] Oz A. Black Box. London: Penguin Random House UK; 1986. 